\title{
Characterization of Pyroligneous Acid used in Agriculture by Gas Chromatography-Mass Spectrometry
}

\author{
João Batista G. Souza, ${ }^{*, a}$ Nilva Ré-Poppi ${ }^{a}$ and Jorge Luiz Raposo Jr. ${ }^{b}$ \\ ${ }^{a}$ Departamento de Química, Universidade Federal de Mato Grosso do Sul, CP 549, \\ Av. Senador Fillinto Muller No. 1555, 79080-190 Campo Grande-MS, Brazil \\ ${ }^{b}$ Faculdade de Ciências Exatas e Tecnologia, Universidade Federal da Grande Dourados, \\ CP 533, 79804-970 Dourados-MS, Brazil
}

\begin{abstract}
Neste estudo, dois tipos de pirólise líquida foram realizados, uma produzida em laboratório e outra adquirida de uma companhia que fornece produtos agrícolas. As análises foram feitas por cromatografia gasosa com detecção através de ionização de chama (GC-FID) e espectrometria de massa (GC-MS). Os correspondentes perfis para as duas amostras são discutidos. Siringol, 1,2,3-trimetoxibenzeno, 2-metoxi-4-metilfenol, o-guaiacol e 5-tert-butilpirogalol foram as substâncias mais abundantes na extração ácida (ácido pirolenhoso + alcatrão solúvel). A composição dos líquidos pirolíticos foi caracterizada principalmente por metoxifenóis (guaiacol, siringol e seus derivados), fenóis, ácidos carboxílicos (C5-C17) e em uma menor quantidade para álcoois (C5-C9), cetonas (C7-C8) e aldeídos (C5-C7). Os resultados para o fertilizante foliar mostraram a presença de alcatrão solúvel e ácido pirolenhoso.
\end{abstract}

In this study, two kinds of samples of pyrolysis liquid were analyzed, one produced at laboratory and other acquired from a company that supplies agricultural inputs. The analyses were carried out by gas chromatography with flame ionization detector (GC-FID) and mass spectrometry (GC-MS). The profiles corresponding to the two samples are discussed. Syringol, 1,2,3-trimethoxybenzene, 2-metoxy-4-methylphenol, o-guaiacol and 5-tert-butylpyrogalol were the most abundant substances in the acid extract (pyroligneous acid + soluble tar). The composition of the pyrolysis liquids was mainly characterized for methoxyphenols (guaiacol, syringol and their derivatives), phenols, carboxylic acids (C5-C17) and in a smaller amount for alcohol (C5-C9), ketones (C7-C8) and aldehydes (C5-C7). The results for the foliar fertilizer showed the presence of soluble tar and pyroligneous acid.

Keywords: biomass, thermal degradation, pyrolysis liquids, retention indices

\section{Introduction}

Pyrolysis is the thermal decomposition of organic material in the absence of oxygen or when the oxygen is present in amount significantly less than required for complete combustion. Wood pyrolysis is a route for the production of charcoal (biochar-solid), tar (liquid) and gaseous products as possible alternate sources of energy. ${ }^{1}$ The process can be adjusted to favor charcoal, pyrolysis liquid, gas, or methanol production with a $95.5 \%$ fuel-to-feed efficiency. ${ }^{2}$ Temperature is the most important factor for the product distribution of pyrolysis. At higher temperatures, the rather large molecules present in the liquid and residual

*e-mail: j.ba@bol.com.br solid are broken down to produce smaller molecules which enrich the gaseous fraction. Low temperatures and high residence times favor the production of charcoal, while the higher temperatures and short residence times lead to high liquid production. ${ }^{1,3}$ Pyrolysis liquid is referred in the literature by terms such as pyroligneous tar, pyrolysis oil, bio-oil, bio-crude oil, bio-fuel oil, wood liquid, wood oil, liquid smoke, pyroligneous acid and wood distillates. ${ }^{3,4}$ In Brazil, pyroligneous acid is the name given at acid aqueous liquid of color reddish-brown. This is obtained in the fractionation of the pyrolysis liquids that are generated in the process of making charcoal. Recently, there have been growing interests in the analysis of chemical constituents of pyroligneous acid. Large number of substances has been found in the pyrolysis liquids from different resources. 
The detected substances from the acids belong to different classes of organic compounds, namely, aldehydes, ketones, alcohols, organic acids, esters, derivatives of furan and pyran, phenolics, hydrocarbons and nitrogen compounds, in which the major ones are organic acids and phenolics. ${ }^{4-12}$

Pyroligneous acid has been used for ages as sterilizing agent, deodorizer, fertilizer and antimicrobial. ${ }^{13}$ The strong antimicrobial activity of pyroligneous acid was correlated to its high contents of organic acids and phenolic substances. ${ }^{5-17}$ When the acid was separately applied or mixed with other acids in dilutions from 300 to 600 times, it proved to be useful in the control of curses and diseases of plants. ${ }^{18}$

Pyroligneous acid also exhibits antioxidant activity. Loo et $a l .{ }^{13}$ studied free radical scavenging activity and antioxidant activity of the pyroligneous acid from a mangrove plant (Rhizophora apiculata), and found that concentrated pyroligneous acid extract exhibited superior free radical scavenging activity with $\mathrm{EC}_{50}$ value of $0.1235 \mathrm{mg} \mathrm{mL}^{-1}$, or $80.96 \%$ of free radical scavenging capability. The three kinds of pyroligneous acid that were prepared from walnut shell at different temperature ranges exhibited antioxidant activity. ${ }^{13}$ The collected acid from high temperature range $\left(311-550^{\circ} \mathrm{C}\right)$ showed the strongest antioxidant activity. ${ }^{14}$ It was considered that the strongest antioxidant activity of the sample was due to its highest content of phenols among the three acids.

Some beneficial effects on the root development and in the production were observed in several kinds of culture, mainly in rice (Oryza Sativa L.), ${ }^{15}$ sorghum (Sorghum bicolor L. Moench) ${ }^{16}$ and sweet potato (Ipomoea potatoes L.). ${ }^{17}$

Despite of the advocated effects for the pyroligneous extract, there is little scientific information that may support the use of this product, especially with regard to environmental contamination due to the presence of polycyclic aromatic hydrocarbons (PAHs). PAHs are byproducts of high temperature pyrolysis and incomplete combustion reactions of fossil fuels and other organic substances. Because some common PAHs are known to be potent carcinogens, this contaminant class is generally regarded as a high priority for environmental pollution regulation. $\mathrm{PAH}$ are substances present in the wood tar insoluble in water. ${ }^{18}$ Pyroligneous acid is marketed in Brazil without going by a quality control even due to product complexity that requires the use of analysis methods of high cost (gas chromatography with mass spectrometry, GC-MS).

Three phases are obtained in decanting of pyroligneous extract: the superior that contains light oils, the inferior that is composed by the tar and the central phase that is the appropriate pyroligneous acid to be used in agriculture, after suitable dilutions for each specific case. ${ }^{19}$

Our objectives in this study were (i) to produce pyrolysis liquids in laboratory from Eucalyptus sp., (ii) to perform the chemical characterization of tar soluble and of pyroligneous acid and (iii) to study the chemical composition a foliar fertilizer and make a contribution to understanding the composition of this.

\section{Experimental}

\section{Instrumentation}

A Varian GC-MS-MS system comprising of a CP-3900 gas chromatograph (Walnut Creek, USA) with an 1177 injector, CP-8410 autosampler and an ion-trap mass spectrometry (Varian Saturn 2100T) was used to establish the real composition of the samples. The analyses were carried out using two different stationary phases for calculate. The first VF-5ms Factor Four (Varian, Walnut Creek, USA) fused silica capillary column (30 $\mathrm{m} \times 0.25 \mathrm{~mm}$ i.d., $0.25 \mu \mathrm{m}$ film thickness), and the second DB-WAX (J\&W Scientific, USA) fused silica capillary column $(30 \mathrm{~m} \times 0.25 \mathrm{~mm}$ i.d., $0.25 \mu \mathrm{m}$ film thickness). The oven temperature for the VF-5ms column was programmed as follows: $1 \mathrm{~min}$ at $60{ }^{\circ} \mathrm{C}$ and then, heated at $6^{\circ} \mathrm{C} \mathrm{min}-1$ to $280^{\circ} \mathrm{C}$ (held for $3 \mathrm{~min}$ ). The injector temperature was maintained at $280{ }^{\circ} \mathrm{C}$. The conditions for analyses with the DB-WAX column were: injector temperature at $240{ }^{\circ} \mathrm{C}$, oven temperature program held at $60^{\circ} \mathrm{C}$ for $1 \mathrm{~min}$ and after, increased at $5^{\circ} \mathrm{C} \mathrm{min}{ }^{-1}$ to $240{ }^{\circ} \mathrm{C}$. The GC was equipped with a split/splitless injector and, an injection volume of $1.0 \mu \mathrm{L}$ was done with a $30: 1$ split ratio. Helium (99.999\% purity, Brazil) was used as carrier gas at a constant flow of $1.0 \mathrm{~mL} \mathrm{~min}^{-1}$. The manifold, transfer line and the ion trap temperatures were set at 120, 280 and $150{ }^{\circ} \mathrm{C}$, respectively. The MS scan parameters included a mass range of 45-500 amu, scan interval of $0.3 \mathrm{~s}$ and electron impact ionization mode at $70 \mathrm{eV}$ were employed. The identification of the substances was based on the comparison of their mass spectra with those in NIST 2.0 and Saturn Library, as well as by comparison of their retention indices with existing literature data.

A Varian CP-3800 (Walnut Creek, CA, USA) gas chromatography equipped with flame ionization detector was used for semi-quantitative analysis. The injection of samples was performed in the splitless mode using a Varian CP-8410 autosampler. Separation was carried out through DB-WAX (J\&W Scientific, USA) fused silica capillary column (30 $\mathrm{m} \times 0.25 \mathrm{~mm}$ I.D.; film thickness: $0.25 \mu \mathrm{m})$. The oven temperature was programmed from $60{ }^{\circ} \mathrm{C}(1 \mathrm{~min})$ 
to $240{ }^{\circ} \mathrm{C}$ at $5^{\circ} \mathrm{C} \mathrm{min}^{-1}$ and held for $3 \mathrm{~min}$. The injector and detector temperatures were maintained at 250 and $300{ }^{\circ} \mathrm{C}$, respectively. Helium (99.999\% purity, Brazil) was used as carrier gas at $1 \mathrm{~mL} \mathrm{~min}^{-1}$ flow rate to carry out $1.0 \mu \mathrm{L}$ of the injection volume. The Varian Star Chromatography Workstation (version 6.0) and StarDHA ${ }^{\mathrm{TM}}$ software were used for instrument control and data handling.

In order to determine the retention indices (RI), a series of n-alkanes $\left(\mathrm{C}_{8}-\mathrm{C}_{22}\right)$ mixture was analyzed under the same operative conditions on VF-5ms and DB-WAX columns and the substance indices were calculated according to van den Dool and Kratz. ${ }^{20}$ The relative contents of compounds were measured by their peak areas in gas chromatography. The used method to quantify the substances of major interest in the extract was internal standardization using calibration curves that were obtained by fitting peak area ratios versus concentration.

\section{Solvents and chemical standard}

The chromatographic solvents such as methanol and dichloromethane (Mallinckrodt Chemical ${ }^{\circledR}$, St. Loius, USA) were utilized to prepare the solution containing the extraction phase. Recovery values for the extraction process were determined in 4-methoxyphenol (98\% purity, Aldrich ${ }^{\circledR}$, St. Louis, USA). The homologous series of n-alkanes $\left(\mathrm{C}_{8}-\mathrm{C}_{22}\right)$ from Sigma ${ }^{\circledR}$ (St. Louis, USA) were used for calculating retention index (RI). Quantification standards used: $o$-cresol, $p$-cresol, 2-methoxy-4-methylphenol, 2-methoxyphenol and 2,6-dimethoxyphenol (97-98\% purity, Fluka) and 1,3,3-trimethoxybenzene(97\% purity, Aldrich).

\section{Sample and sample preparation}

Two different kinds of pyroligneous liquid samples were used in this study: one produced in the laboratory and other from a commercial foliar fertilizer company. The foliar fertilizer samples were purchased from a mining company that markets the product in $7.0 \mathrm{~mol} \mathrm{~L}^{-1}$ of pyroligneous extract. This liquid fertilizer is produced from wood pyrolysis that is obtained during the charcoal production. Laboratory samples were obtained using a muffle furnace with a round bottom flask and a fractionating column inside the furnace. A tube was connected the column to the condenser and, pyrolysis liquids were collected in a glass flask. Masses of $200 \mathrm{~g}$ (Eucalyptus sp.) were weighed with accuracy for the procedure. The furnace was heated to $100{ }^{\circ} \mathrm{C}$ and a gradual increase of $10{ }^{\circ} \mathrm{C}$ was made $10 \mathrm{~min}$ intervals until to obtaining the liquid condensation. ${ }^{14}$ The temperatures of liquid distillations are shown in Table 1.
Table 1. Temperature of liquids obtained from Eucalyptus sp. distillation

\begin{tabular}{lc}
\hline Furnace temperature $/{ }^{\circ} \mathrm{C}$ & Physical characteristics \\
\hline 160 & colorless liquid \\
260 & yellow liquid \\
360 & viscous liquid of black color \\
410 & viscous liquid of black color \\
\hline
\end{tabular}

Laboratory samples of pyroligneous acid and the commercial pyroligneous extract $\left(7.0 \mathrm{~mol} \mathrm{~L}^{-1}\right)$ were submitted to solid phase extraction (SPE) using $\mathrm{C}_{18}$ cartridge (Supelco, Bellefonte, USA). A $\mathrm{C}_{18}$ SPE cartridge was prewashed with $10 \mathrm{~mL}$ dichloromethane, $10 \mathrm{~mL}$ methanol and $10 \mathrm{~mL}$ methanol/water (1:9). For the extraction of organic substances, $2 \mathrm{~mL}$ of commercial pyroligneous acid were directly transferred to the cartridge. After the passage of the liquid through SPE, the cartridge was washed with $10 \mathrm{~mL}$ of methanol/water (1:9). The retained substances in the $\mathrm{C}_{18}$ cartridge were eluted with $10 \mathrm{~mL}$ of methanol, the fraction was collected in a $10 \mathrm{~mL}$ volumetric flask and the final volume was adjusted with methanol. Recovery tests for the extraction procedure was done by analyzing $2.0 \mathrm{~mL}$ of the 4-methoxyphenol solution in the $126 \mathrm{mg} \mathrm{L}^{-1}$ concentration and by spiking $0.253 \mathrm{mg}$ of 4-methoxyphenol in the pyroligneous extract. Recoveries between 95 and $110 \%$ were obtained.

\section{Separation and definition of the condensed fractions}

The total extracted of the pyroligneous acid was fractioned according to the diagram shown in Figure 1. The aqueous phase (extract acid) was separated from the insoluble tar by decantation process. The extract acid was submitted to a simple distillation to separate pyroligneous acid of the soluble tar. At $120^{\circ} \mathrm{C}$, the distillation of the pyroligneous acid began and the temperature was kept constant until the end of the distillation. The distillation produced a dense and dark residue (soluble tar). The soluble

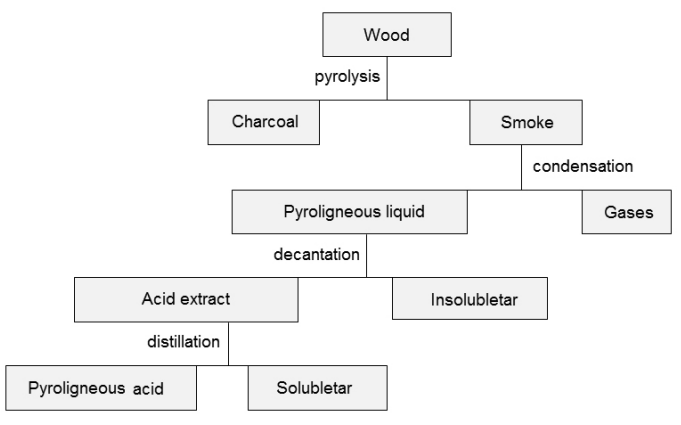

Figure 1. Fractionation scheme of the pyroligneous acid obtained from pyrolysis of wood. ${ }^{21}$ 
tar and the pyroligneous acid were analyzed by GC-FID and GC-MS techniques.

\section{Fractionation of soluble tar}

Masses of $0.500 \mathrm{~g}$ of soluble tar were dissolved in $20 \mathrm{~mL}$ of methanol. After, a $10 \% \mathrm{NaOH}$ solution was added up to $\mathrm{pH} 13.5$ to convert and to extract the phenolic substances into water-soluble phenolate ions and, the solution was filtered through a quartz fiber membrane (0.45 $\mu \mathrm{m}$ pore size). At room temperature, the aqueous phase was acidified down to $\mathrm{pH} 2$ with hydrochloric acid and, a phenolic-rich fraction was recovered by three consecutive extractions with $50 \mathrm{~mL}$ of dichlromethane ( $50 \mathrm{~mL}$ of the aqueous phase). After, a second fraction was obtained by three consecutive extractions with $50 \mathrm{~mL}$ each of dichloromethane-ether (1:3). The organic extracts were combined, the volume was reduced in a rotary evaporator system (bath temperature at $30^{\circ} \mathrm{C}$ ) and the final volume was adjusted up to $10 \mathrm{~mL}$ in a volumetric flask.

\section{Results and Discussion}

\section{Laboratory sample (tar soluble and pyroligneous acid)}

The dry distillation of Eucalyptus sp. wood (200 g) produced $79.9 \mathrm{~g}$ of charcoal $(40.0 \%), 114.6 \mathrm{~g}$ of pyroligneous liquid (57.3\%) and around $2.7 \%$ of gases (Figure 1). $110 \mathrm{~mL}$ of acid extract $(107.3 \mathrm{~g}$ ) and $7.4 \mathrm{~g}$ of insoluble tar were obtained by decantation from pyroligneous liquid (yield: $53.7 \%$ and $3.7 \%$ of the mass of wood, respectively). In the distillation of the acid extract at $120{ }^{\circ} \mathrm{C}, 90 \mathrm{~mL}$ of the pyroligneous acid $(91.0 \mathrm{~g})$ and $16.3 \mathrm{~g}$ of the soluble tar were collected $(45.5$ and $8.1 \%$ of the wood mass, respectively).
These values were relatively high when compared with those obtained from the wood pyrolysis at atmospheric pressure. Depending on the wood, it is usually to obtain ranges of $37-50 \%$ of coal, $4-11 \%$ of tar, $30-36 \%$ of condensate liquid and $14-29 \%$ of uncondensed gases. ${ }^{22}$

The identified organic substances in soluble tar are shown in Table 2 with their GC retention indices and relative composition (\%). In this study, twenty four substances were identified in the extracts of dichloromethane (Fr.1 fraction) from the soluble tar. The major substances in the Fr.1 fraction were 3-methyl-1,2-cyclopentanedione (5.1\%), syringol (35\%), 1,2,3-trimethoxybenzene (24.6\%) and 5-tert-butylpyrogalol (10.8\%). The concentrations of the quantified substances ranged between 0.2 and $6.1 \mathrm{~g} \mathrm{~kg}^{-1}$ of extract.

Phenols and methoxyphenols (products of the thermal degradation of the lignin) represented more than $60 \%$ of the fraction (Fr.1). Ketone group represented $7.7 \%$ of the total fraction. The mass of the Fr.1 fraction represented $1.7 \%$ of the soluble tar mass and $1.5 \%$ of the condensed liquids mass resulting in a $0.8 \%$ of gain in relation to the mass of wood.

Thirty one substances were identified in Fr.2. In this extract, $44 \%$ corresponds to carboxylic acid esters. Alcohols were identified in a considerable number, ca. $17.3 \%$ of the total fraction. The identified alcohols in this fraction presented six or more carbons in the molecule. The mass of the fraction Fr. 2 represented $0.9 \%$ of the total tar mass, $0.8 \%$ of condensed liquids and $0.4 \%$ in relation to the wood mass.

Pyroligneous acid, that was collected by distillation from acid extract (Figure 1), contained mainly aldehydes, furans, guaiacol and 2-metoxy-4-methylphenol, syringol and 1,2,3-trimethoxibenzene in smaller proportion. Figure 2 shows the chromatogram obtained from GC-FID analysis of pyroligneous acid. The acetic acid, methanol and water

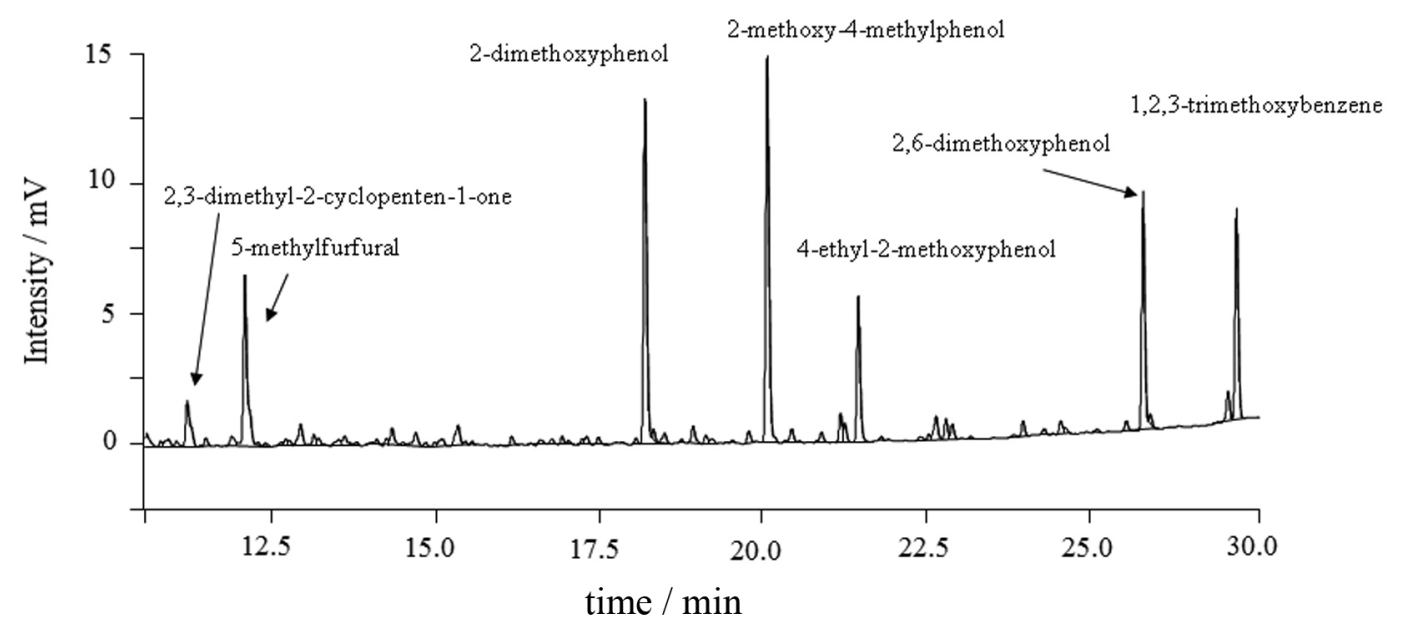

Figure 2. Chromatogram obtained by CG/FID analysis of pyroligneous acid. 
components of pyroligneous acid were eliminated during the sample preparation. The results from the analyzed fraction represented $1.2 \%$ of the total mass of the obtained pyroligneous acid and $0.95 \%$ of the total mass of the condensed liquids. These values correspond to $0.5 \%$ of the initial wood mass. The main found substances were: 2-methoxy-4-methylphenol (16.8\%), 2-methoxyphenol (o-guaiacol-14.4\%), 2,6-dimethylphenol (syringol-9.7\%), 1,2,3-trimethoxybenzene (9.2\%), 5-methylfurfural $(8.5 \%)$ and 4-ethyl-2-methoxyphenol $(6.4 \%)$, representing $65 \%$ of the fraction. Low concentrations of the quantified substances in the pyroligneous acid were determined, and were between 0.2 and $2.0 \mathrm{~g} \mathrm{~L}^{-1}$. Phenols (2,6-dimethylphenol, 2-methylphenol, 3-methylphenol, 4-methylphenol, 2,5-dimethylphenol, 3-ethylphenol, 3,5-dimethylphenol and 2,3-dimethylphenol) and methoxyphenols (2-metoxyphenol, 2-metoxy-5-methylphenol, 2-methoxy-4-methylphenol, 4-ethyl-2-methoxyphenol, 2,6-dimethoxyphenol) represented $50 \%$ in weight of the total fraction. In this study, a total of 63 substances in the pyroligneous extract were identified, characterized mainly by methoxyphenols (guaicol, syringol and its derivatives), phenols and ethers. The total mass of the identified substances correspond to $3.5 \%$ of the initial mass of wood.

\section{Chemical characterization of foliar fertilizer}

The GC-FID chromatogram of foliar fertilizer sample is presented in Figure 3. Phenols and its derivatives and methoxyhenols were identified. Syringol was the most abundant substance (17.8\%). Others substances such as 2-methoxyphenol (o-guaiacol), 2-methoxy-4-methylphenol and 1,2,3-trimethoxybenzeno were identified with 16.7, 14.1 and $8.1 \%$, respectively. The obtained concentrations in foliar fertilizer for the evaluated substances were between 6.2 and $37.5 \mathrm{~g} \mathrm{~L}^{-1}$, these values were higher than those found in the obtained acid by distillation in the laboratory. The substances 2,6-dimethylphenol, 2,5-dimethylphenol, 3-ethyphenol and 3,5-dimethylphenol were identified only in the sample of the foliar fertilizer. The substances trimethyl-2-cyclopenten-1-one and 4,4-dimethy12-cyclohexen-1-one (ketones) and methyl-2-furoate were only identified in pyroligneous acid. The preparation form of the two samples can be responsible for differences in concentration and number of identified substances between the pyroligneous acid and the foliar fertilizer. The commercial product specifies on the label a content of pyroligneous extract close to $7.0 \mathrm{~mol} \mathrm{~L}^{-1}$. The results show that the foliar fertilizer was prepared by diluting of the acid extract after decanting, so it contains substances of the soluble tar. The presence of the soluble tar causes an increase in the concentration of the substances in the foliar fertilizer (commercial product), while the pyroligneous acid of laboratory was obtained by distillation process of the pyroligneous extract at $120{ }^{\circ} \mathrm{C}$. The manufacturer of the foliate fertilizer does not identify the wood or the conditions of carbonization to obtain the final product. The biomass and the conditions of carbonization determine the composition $^{23}$ and the concentrations of the substances ${ }^{24,25}$ in the pyroligneous acid. The observed differences between the two studied samples can be due to the differences in the process of obtaining and the species of carbonized wood. ${ }^{26}$

Table 2. Probable identity of phenol, metoxyphenol and other organic substances identified in the samples and the relative percentage extract

\begin{tabular}{|c|c|c|c|c|c|c|c|c|c|}
\hline \multirow{3}{*}{ Substances } & \multirow{3}{*}{$M$} & \multicolumn{3}{|c|}{$\mathrm{GC} \mathrm{I}_{\mathrm{R}}$ data set } & \multirow{3}{*}{ Ions $^{\text {a }} / \mathrm{m} / \mathrm{z}$} & \multicolumn{4}{|c|}{ Relative composition / \% } \\
\hline & & \multirow{2}{*}{$\mathrm{VF}-5 \mathrm{~ms}$} & \multirow{2}{*}{ DB-WAX } & \multirow{2}{*}{ Literature } & & \multirow{2}{*}{$\begin{array}{c}\text { Foliar } \\
\text { fertilizer }\end{array}$} & \multicolumn{2}{|c|}{ Soluble tar } & \multirow{2}{*}{$\begin{array}{c}\text { Pyroligneous } \\
\text { acid }^{\text {a }} \\
\end{array}$} \\
\hline & & & & & & & Fr.1 & Fr.2 & \\
\hline 2,4-Dimethyl-4-octanol & 158 & & 1203.4 & & $101 ; 57 ; 83$ & & & 2.2 & \\
\hline 2,2-Diethyl-1,3-dioxolane & 130 & & 1208.5 & & $101 ; 57$ & & & 5.1 & \\
\hline 2,6,6-Trimethyl-1-heptene & 140 & & 1213.3 & & $57 ; 69 ; 56$ & & & 1.4 & \\
\hline 3,4-Dimethyl-3-pentanol & 116 & & 1218.5 & & $43 ; 55,70$ & & & 7.4 & \\
\hline Hexyl-2-butanoate & 170 & & 1226.1 & & $69 ; 87 ; 56$ & & & 1.1 & \\
\hline 2-Ethyl-4-methylbenzene & 120 & & 1230.7 & & $105 ; 120 ; 106$ & & & 1.1 & \\
\hline Cyclobutanecarboxylic acid,-2-butylester & 156 & & 1255.1 & & $55 ; 83 ; 73$ & & & 7.1 & \\
\hline 1-Ethyl-3-methylbenzene & 120 & 1000.6 & 1266.6 & & $105 ; 120 ; 91$ & & & 0.4 & \\
\hline Cyclobutanecarboxylic acid, -propylester & 142 & & 1276.7 & & $55 ; 101 ; 83$ & & & 3.8 & \\
\hline 1,3,5-Trimethylbenzene & 120 & 1027.1 & 1286.9 & & $105 ; 120 ; 119$ & & & 1.1 & \\
\hline 2-Ethyl-hexanoic acid & 144 & & 1293.9 & & $73 ; 88 ; 57$ & & & 0.9 & \\
\hline 5-Methyl-3-heptanol & 130 & & 1296.5 & & $59 ; 57 ; 83$ & & & 2.2 & \\
\hline Acid cyclobutanecarboxylic-pentyl ester & 156 & & 1310.5 & & $55 ; 101 ; 83$ & & & 7.3 & \\
\hline Cyclobutanecarboxylic acid, heptylester & 198 & & 1313.8 & & $55 ; 101 ; 83$ & & & 4.7 & \\
\hline 3,4-Dimethyl-3-heptanol & 144 & & 1323.5 & & $73 ; 55 ; 83$ & & & 1.0 & \\
\hline 2,4-Dimethyl-3-heptanol & 144 & 1087.1 & 1362.84 & & $73 ; 55 ; 83$ & & & 0.5 & \\
\hline
\end{tabular}


Table 2. continuation

\begin{tabular}{|c|c|c|c|c|c|c|c|c|c|}
\hline \multirow{3}{*}{ Substances } & \multirow{3}{*}{$M$} & \multicolumn{3}{|c|}{$\mathrm{GC} \mathrm{I}_{\mathrm{R}}$ data set } & \multirow{3}{*}{ Ions $\mathrm{s}^{\mathrm{a}} \mathrm{m} / \mathrm{z}$} & \multicolumn{4}{|c|}{ Relative composition / \% } \\
\hline & & \multirow{2}{*}{ VF-5ms } & \multirow{2}{*}{ DB-WAX } & \multirow{2}{*}{ Literature } & & \multirow{2}{*}{$\begin{array}{l}\text { Foliar } \\
\text { fertilizer }\end{array}$} & \multicolumn{2}{|c|}{ Soluble tar } & \multirow{2}{*}{$\begin{array}{c}\text { Pyroligneous } \\
\text { acid }^{\mathrm{a}}\end{array}$} \\
\hline & & & & & & & Fr.1 & Fr.2 & \\
\hline Pentanoic acid, 6-ethyl-3-octyl-ester & 242 & 1110.3 & 1378.34 & & $85 ; 84 ; 57$ & & & 5.3 & \\
\hline 3-Ethyl-3-methyl-2-pentanol & 130 & & 1386.3 & & $84 ; 69 ; 85$ & & & 0.8 & \\
\hline Trimethyl-2-cyclopenten-1-one & 124 & & 1434.5 & & $109 ; 124 ; 81$ & & & & 0.2 \\
\hline Trimthyl-2-cyclopenten-1-one & 124 & & 1454.6 & & $109 ; 124 ; 81$ & & & & 0.4 \\
\hline 2,3-Dimethyl-2-cyclopenten-1-one & 110 & 1035.3 & 1466.0 & & $67 ; 110 ; 95$ & 3.5 & 0.1 & & 2.6 \\
\hline 1-Butanol-4[(tetraidro-2H-pyran-2-yl)oxy] & 174 & & 1465.2 & & $85 ; 73 ; 55$ & & & 0.7 & \\
\hline 5-Methylfurfural & 110 & & 1504.4 & & $110 ; 109 ; 53$ & 1.1 & & & 8.5 \\
\hline 3-Ethyl-2-hydroxy-2-cyclopenten-1-one & 126 & & 1513.39 & & $126 ; 55 ; 83$ & & 0.1 & & \\
\hline Methyl-2-furoate & 126 & & 1515.0 & & $95 ; 126 ; 67$ & & & & 0.87 \\
\hline 2-Acetyl-5-methylfuran & 124 & & 1541.3 & & $109 ; 124 ; 53$ & 1.0 & & & 1.3 \\
\hline 1,2,4,5-Cyclohexanetetrol & 148 & & 1550.1 & & $57 ; 73 ; 60$ & & & 2.3 & \\
\hline 3-Ethyl-2-cyclopenten-1-one & 110 & & 1550.3 & & $81 ; 110 ; 53$ & 0.8 & & & 0.5 \\
\hline 2,5-Dihydro-3,5-dimethyl-2-furanone & 112 & & 1553.6 & & $69 ; 112 ; 97$ & & 0.1 & & \\
\hline Ethyl-3-methyldecanoate & 214 & & 1571.3 & & $88 ; 115 ; 70$ & & & 0.27 & \\
\hline 4-Ethyl-2-hydroxy-2-cyclopent-1-one & 126 & & 1629.2 & & $97 ; 69 ; 126$ & & 0.1 & & \\
\hline a- $d$-Riboside-1-o-dodecyl & 318 & & 1636.1 & & $73 ; 60 ; 57$ & & & 0.2 & \\
\hline 2-Cyclopentene-1-carboxylic acid & 112 & & 1641.9 & & $67 ; 112 ; 65$ & & 0.1 & & \\
\hline 4,4-Dimethyl-2-cyclohexen-1-one & 124 & & 1650.7 & & $124 ; 82 ; 96$ & & & & 1.3 \\
\hline 3,5-Dimethyl 2-hydroxy-2-cyclopenten-1-one & 126 & & 1701.5 & & $126 ; 111 ; 69$ & & 0.2 & & \\
\hline 3-Methyl-1,2-cyclopentanedione & 112 & & 1735.2 & & $112 ; 84 ; 69$ & & 5.1 & & \\
\hline 2-Methoxyphenol (o-guaiacol) & 124 & 1193.4 & 1783.1 & $1093.1^{\mathrm{b}}$ & $109 ; 124 ; 81$ & 16.70 & 1.6 & & 14.4 \\
\hline 3-Methyl-2(5H)-furanone & 98 & & 1790.0 & & $69 ; 98$ & & 0.2 & & \\
\hline 2-Methoxy-5-methylphenol & 138 & 1176.7 & 1788.7 & & $138 ; 123 ; 95$ & 0.6 & & & 0.6 \\
\hline 2-Hydroxy-2-ethyl-2-cyclopenten-1-one & 126 & & 1802.2 & & $126 ; 55 ; 83$ & & 0.8 & & \\
\hline 2,6-Dimethylphenol & 122 & 1105.2 & 1818.9 & & $122 ; 107 ; 77$ & 0.8 & & & \\
\hline 2-Hydroxy-3-methyl-2-cyclo-1-one & 112 & & 1836.6 & & $112 ; 69 ; 55 ; 83$ & & & 6.2 & \\
\hline 1,4-Dimethoxybenzene & 138 & 1184.9 & 1861.2 & & $123 ; 138 ; 95$ & 0.9 & & & 0.6 \\
\hline 2-Methoxy-4-methylphenol & 138 & 1197.6 & 1876.6 & $1196.7^{\mathrm{b}}$ & $138 ; 123 ; 95$ & 14.08 & 1.4 & & 16.8 \\
\hline Phenol & 94 & & 1909.0 & & $94 ; 66 ; 65$ & & 0.4 & & \\
\hline 2-Methylphenol (o-cresol) & 108 & 1054.2 & 1933.8 & $1052.9^{\mathrm{c}}$ & $108 ; 107 ; 79$ & 6.2 & & & 1.2 \\
\hline 4-Ethyl-2-methoxyphenol & 152 & 1285.5 & 1947.4 & $1285.6^{\mathrm{c}}$ & $137 ; 152 ; 122$ & 3.34 & 0.6 & & 6.4 \\
\hline 3,6-Dimethyl-3-octanol & 158 & & 1990.5 & & $73 ; 55 ; 43$ & & & 0.33 & \\
\hline 2-Hydroxy-2,4,6-cycloheptathriene-1-one & 122 & & 2003.4 & & $122 ; 94 ; 66$ & & 0.2 & & \\
\hline 3-Methylphenol & 108 & 1074.0 & 2008.9 & $1073.2^{\mathrm{c}}$ & $108 ; 107 ; 77$ & 4.96 & 0.2 & & \\
\hline 4-Methylphenol ( $p$-cresol) & 108 & & 2017.4 & & $107 ; 108 ; 77$ & 6.94 & 0.1 & & 0.7 \\
\hline 2,5-Dimethylphenol & 122 & 1148.1 & 2072.3 & $1148.3^{\mathrm{c}}$ & $122 ; 107 ; 77$ & 0.40 & & & \\
\hline 3-Ethylphenol & 122 & 1137.8 & 2098.1 & $1137.9^{c}$ & $107 ; 122 ; 77$ & 1.30 & & & \\
\hline 3,5-Dimethylphenol & 122 & 1168.4 & 2105.0 & $1166.7^{\mathrm{c}}$ & $107 ; 122 ; 121$ & 0.40 & & & \\
\hline 2,3-Dimethylphenol & 122 & - & 2142.8 & & $107 ; 122 ; 77$ & 0.64 & & & 0.4 \\
\hline 2,6-Dimethoxyphenol (syringol) & 154 & 1357.1 & 2182.0 & $1356.1^{\mathrm{b}}$ & $154 ; 139 ; 93$ & 17.8 & 35.0 & 1.6 & 9.7 \\
\hline 1,4,3,6-Dianhydro-a- $d$-glucopyranose & 144 & & $\mathrm{nc}$ & & $69 ; 57 ; 70 ; 98$ & & & 0.7 & \\
\hline Pentanoic acid, 6-ethyl-3-octyl-ester & 242 & 1110.3 & & & $85 ; 84 ; 57$ & & & 5.5 & \\
\hline 2-Methoxy-4-propilphenol ( $p$-propylguaiacol) & 166 & 1373.3 & $\mathrm{nc}$ & $1373.3^{\mathrm{b}}$ & $137 ; 166 ; 122$ & & 0.1 & & \\
\hline 4-Alilguaiacol (eugenol) & 164 & & $\mathrm{nc}$ & $1364.5^{\mathrm{c}}$ & $164 ; 149 ; 77$ & & 0.1 & & \\
\hline 1,2,3-Trimethoxybenzene or isomer & 168 & 1449.6 & $\mathrm{nc}$ & $1451.8^{c}$ & $168 ; 153 ; 110$ & 8.1 & 24.63 & & 9.2 \\
\hline 1,2,3-Trimethoxy-5-methylbenzene & 182 & 1523.5 & $\mathrm{nc}$ & & $167 ; 182 ; 53 ; 107$ & 0.5 & 0.1 & & 0.8 \\
\hline 5-Tert-butylpyrogalol & 182 & 1526.2 & $\mathrm{nc}$ & & $167 ; 182 ; 107$ & & 10.8 & & \\
\hline 1(4-Hydroxy-3-metoxyphenyl)ethanone & 166 & & $\mathrm{nc}$ & $1496.6^{\mathrm{b}}$ & $151 ; 166 ; 123$ & & 1.1 & & \\
\hline $\begin{array}{l}\text { 1,2-Benzodicarboxylic acid, bis(2-methylpropyl) } \\
\text { ester }\end{array}$ & 278 & 1865.3 & $\mathrm{nc}$ & & $149 ; 223 ; 104$ & & & 7.6 & \\
\hline
\end{tabular}

$\mathrm{I}_{\mathrm{R}}=$ Retention index values of non-polar and polar capillary columns: VF-5ms (5\% phenyl 95\% dimethylpolysiloxane) and DB-WAX (polyethylene glycol); Fr.1 and Fr.2 extracts, dichloromethane and dichloromethane-ether, respectively; ${ }^{\text {athe }}$ three more abundant ions of the spectrum of masses; ${ }^{\mathrm{b}} \mathrm{Hawthorne}$ et al. $;^{27}$ 'Ré-Poppi and Santiago-Silva; ${ }^{28} \mathrm{nc}=$ retention indices not calculated. 


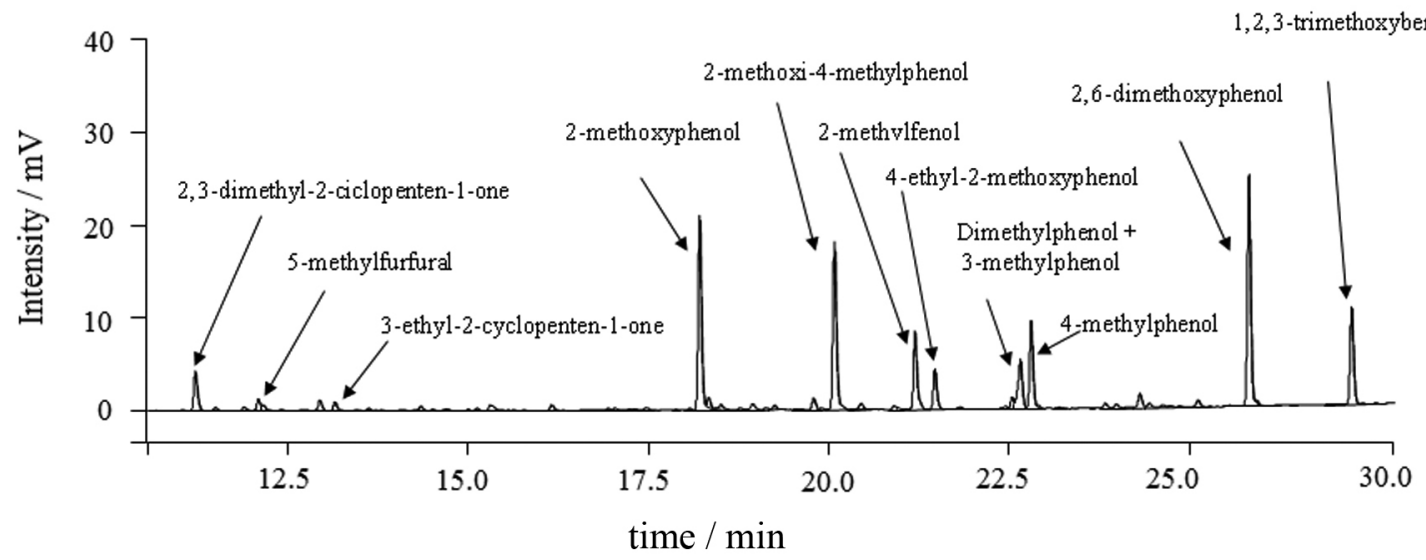

Figure 3. Chromatogram obtained by GC-FID analysis of the foliar fertilizer.

\section{Conclusions}

In this study, 63 substances were identified in the acid extract (pyroligneous acid + soluble tar), methoxyphenol was the group of a larger representation. Syringol, 1,2,3-trimethoxybenzene, 2-metoxy-4-methylphenol, $o$-guaiacol and 5-tert-butylpyrogalol were the most abundant substances in the acid extract. The main identified substances in the pyroligneous acid that was obtained in the laboratory were 2-methoxy-4-methylphenol, guaiacol, syringol, 5-methyl furfural, 1,2,3-trimethoxybenzene and 4-ethyl-2-methoxyphenol, and these substances represented $75 \%$ of the relative composition. The concentrations of syringol, guaiacol, 2-methoxy-4-methylphenol, 1,2,3-trimethoxybenzene, 4-methylphenol and $o$-cresol were of 15 to 30 times higher in the commercial foliar fertilizer than the pyroligneous acid from the laboratory, which seems to suggest that this was prepared from acid extract (pyroligneous acid + soluble tar).

\section{Acknowledgments}

The authors are grateful to the Conselho Nacional de Desenvolvimento Científico e Tecnológico (CNPq) and to the Fundação de Apoio ao Desenvolvimento do Ensino Ciência e Tecnologia de Mato Grosso do Sul (FUNDECT) for fellowships to J. B. G. S and J. L. R. J. and financial support for this research.

\section{References}

1. Balat, M.; Balat, M.; Kirtay, E.; Balat, H.; Energy Convers. Manage. 2009, 50, 3147.

2. Demirbas, A.; Prog. Energy Combust. Sci. 2004, 30, 219.

3. Bridgwater, A. V.; Chem. Eng. J. 2003, 91, 87.

4. Loo, A. Y.; Jain, K.; Darah, I.; Food Chem. 2008, 107, 1151.
5. Wei, Q.; Ma, X.; Dong, J.; J. Anal. Appl. Pyrolysis 2010, 87, 24.

6. Guilén, M. D.; Ibargoita, M. L.; J. Agric. Food Chem. 1966, 44, 1302.

7. Guilén, M. D.; Ibargoita, M. L.; J. Sci. Food Agric. 1996, 72, 104.

8. Guilén, M. D.; Manzanos M. J.; J. Agric. Food Chem. 1999, 47, 3016.

9. Guilén, M. D.; Manzanos, M. J.; Ibargoitia, M. L.; J. Agric. Food Chem. 2001, 49, 2395.

10. Guilén, M. D.; Manzanos, M. J.; Food Chem. 2002, 79, 283.

11. Wei, Q.; Ma, X.; Zhao, Z.; Zhang, S.; Lui, S.; J. Anal. Appl. Pyrolysis 2010, 88, 49.

12. Novotny, E. H.; Hayes, M. H. B.; Madari, B. E.; Bonagamba, T. J.; Azevedo, E. R., Souza, A. A.; Song, G.; Nogueira, C. M.; Mangrich, A. S.; J. Braz. Chem. Soc. 2009, 20, 1003.

13. Loo, A. Y.; Jain, K.; Darah, I.; Food Chem. 2007, 104, 300.

14. Wei, Q.; Ma, X.; Zhao, Z.; Zhang S.; Liu, S.; J. Anal. Appl. Pyrolysis 2010, 88, 49.

15. Tsuzuki, E.; Morimitsu, T.; Matsui, T.; Jpn. J. Crop Sci. 2000 , $66,15$.

16. Esechie, H. A.; Dhaliwal, G. S.; Arora, R.; Randhawa, N. S.; Dhawan, A. K.; Proceeding of Ecological Agriculture and Sustainable Development, 1997, Chandigarh, India, 1998.

17. Shibayama, H.; Mashima, K.; Mitsutomi, M.; Arima, S.; Marine and Highland Bioscience Center Report 1998, 7, 15.

18. Souza, J. B. G.; Caracterização dos Líquidos de Pirólise da Madeira na Produção de Carvão; UFMS: Campo Grande, MS, Brasil, 2003, p. 19.

19. Alves, M.; Cazetta, J. O.; Nunes, M. A.; Oliveira, C. A. L.; Colombi, C. A.; Revista Bras. Frutic. 2007, 29, 382.

20. van den Dool, H.; Kratz, P. D.; J. Chromatogr. 1963, 11, 463.

21. Miyasaka, S.; Ohkawara, T. I.; Utsumi, B.; Ácido Pirolenhoso: Uso e Fabricação; Boletim AgroEcológico, Botucatu, SP, Brasil, ano 3, No. 14, 1999. 
22. Amen-Chen, C.; Pakdel, H.; Roy, C.; Biomass Bioenergy 1997, 13,25 .

23. Diebold, J. P.; A Review of the Toxicity of Biomass Pyrolysis Liquids Formed at Low Temperature; USDOE Assistant Secretary for Energy Efficiency and Renewable Energy: Washington, DC (DOI 10.2172/468520).

24. Guille, M. D.; Manzanos, M. J.; Food Chem. 2000, 79, 292.

25. Lingens, A.; Windeisen, E.; Wegener, E.; Wood Sci. Technol. 2005, 39, 49 .
26. Windeisen, E.; Strobel, C.; Wegener, G.; Wood Sci. Technol. 2007, 41, 523.

27. Hawthorne, S. B.; Krieger, M. S.; Miller, D. J.; Mathiason, M. B.; Environ. Sci. Technol. 1989, 23, 470.

28. Ré-Poppi, N.; Santiago-Silva, M. R.; Chromatographia 2002, 55,475 .

Submitted: July 18, 2011

Published online: February 7, 2012 